\title{
Effect of Corn Milk by-product Addition on the Physical Properties of Whole Wheat Bread
}

\author{
Patcharaporn Tinchan, Mayoonkarn Dechkunchorn, and Kunwadee Kaewka* \\ Department of Food Technology and Nutrition, Faculty of Natural Resources and \\ Agro-Industry, Kasetsart University, Chalermprakiat Sakon Nakhon Province Campus, \\ Sakon Nakhon 47000, Thailand \\ *Corresponding author.E-mail: kunwadee.ka@ku.th \\ https://doi.org/10.12982/CMUJNS.2019.0008
}

Received: June 25, 2018

Revised: September 12, 2018

Accepted: September 20, 2018

\begin{abstract}
Corn milk by-product (CMBP) is normally wasted or used as animal feed. In this study, fresh-CMBP (F-CMBP) and powdered-CMBP (P-CMBP) (14, 28 and $42 \%$ whole wheat flour) were used to improve the textural and other physical properties of whole wheat bread (WWB). Bread samples were kept for 6 days, and analyzed at days 0,3 and 6 using room temperature storage. Dough height, bread height, crust color, crumb color, hardness and the specific volume of bread were measured. Fortification with 14 and $28 \%$ F-CMBP increased the specific volume of $W W B$, but lowered the bread height. This indicated the collapsed structure of $W W B$ as the CMBP disturbed the dough and bread structure. F-CMBP and P-CMBP lowered the hardness of WWB compared to traditional WWB. Fortification with $14 \%$ F-CMBP produced the best result, reducing the hardness of $W W B$. However, a greater amount of $F$ - and $P$-CMBP for fortification resulted in a higher hardness value. The WWB samples fortified with $C M B P$ seemed to have increased crust $L *$ values, but decreased $L$ * values for bread crumb color. This study suggested the potential of CMBP as a food ingredient to improve textural and other physical properties of food products.
\end{abstract}

Keywords: Corn milk by-product, Whole wheat bread, Physical property, Textural property 


\section{INTRODUCTION}

Whole grain wheat bread (WGWB) which is recognized for its health benefits, is consumed worldwide. The main ingredient related to its health benefits is the whole grain wheat flour (WGWF). The nutritive composition of WGWF is claimed to contain more fibers, vitamins, minerals and phytochemicals than refined wheat flour. The composition of WGWFs has been approximately reported as $12 \%$ moisture, $15 \%$ protein, $2 \%$ fat, $2 \%$ ash and 12 $16 \%$ dietary fiber (Bressiani et al., 2017). Apart from its nutritional properties, the sensory attributes of WGWB are key factors that drive consumer preference and purchasing decisions. Among the sensory properties of appearance, texture, aroma and flavor, the texture property of WGWB showed a correlation with lowering the consumer liking score (Bernstein and Rose, 2015). Many researchers have undertaken studies to understand and modify the textural properties of whole wheat bread (WWB) through modification of the raw material itself or by adding other ingredients to the recipe. For material modification, physical, chemical and physicochemical treatments had been applied to whole wheat starch and flours. On the other hand, food additives such as gelling agent, food hydrocolloids and emulsifying agent have been added to WWB to improve the textural property. The use of gum Arabic or pectin could improve dough handling properties, loaf specific volume and crumb softness when incorporated into composite corn-wheat pan bread formulation (Yaseen et al., 2010). Similar results were found by Shittu et al. (2009), who studied the use of Xanthan gum for the quality of cassava-wheat bread. Moreover, natural ingredients such as potato starch (Kim et al., 2015) and chestnut flour (Demirkesen et al., 2010) have been included in rice flour added with hydrocolloid and/or gum blends to improve the dough and bread properties in the rice flour in gluten-free breads. Also using natural ingredients in WWB has been reported. The goal of adding natural ingredient is not only to improve the physicochemical properties of WWB, but also provide nutritive fortification. Pathak et al., (2016) revealed that the antioxidant activity in ripe mango peel powder fortified WWB, showing a linear increase with respect to the fortification level.

Corn or maize (Zea mays L.) is commercially used as animal feed or processed to produce corn milk or corn oil for human consumption. In Thailand, corn milk is produced at both the household and industrial scales. It is an alternative drink to dairy products and consumed widely. The by-product of the corn milk process is called corn cake or corn milk by-product (CMBP). It is normally wasted or used as animal feed. The nutritive compositions of defatted corn germ waste from corn oil production have been reported to be a rich source of protein, mostly consisting of albumin and globulin proteins. Its protein ratio was similar to that of soy protein (Siddiq et al., 2009a). Attempts have been made to use corn milk byproduct in food research and the food industry. Siddiq et al. (2009b) studied using defatted corn germ flour, the by-product from corn oil production, in a wheat flour based product. Defatted corn germ flour was blended with wheat flour at levels of 5-25\%. They found that adding defatted corn germ flour in wheat flour improved the oil and water absorption and emulsion capacities of flours. The hardness of dough (indicated by peak force values) increased with higher contents of defatted corn germ flour, indicating the potential of using defatted corn germ flour in wheat flour based products. Moreover, defatted corn germ flour was partially substituted for wheat flours in a biscuit recipe and maintained compatible sensory acceptability with the traditional biscuit with a level of use up to $40 \%$ substitution (Barnwal et al., 2013). 
The utilization of CMBP could potentially be used as a natural ingredient to improve the quality of WWB. In our study, fresh-CMBP (F-CMBP) was dried to powdered-CMBP (P-CMBP) which was more convenient for use and storage. Therefore, this study aimed to evaluate the textural and other physical properties of F-CMBP and P-CMBP fortified WWB.

\section{MATERIALS AND METHODS}

\section{Corn milk process}

The production of corn milk was replicated at the household scale. Sweet corn was bought from a local market and the corn silk and leaves were removed. The corn cobs were washed and the kernel was separated by cutting. The kernels were heated in boiling water for $20 \mathrm{~min}$, and then blended with water in the ratio of corn kernel:water of 1:3, for $1 \mathrm{~min}$ in a food grinder (Model: HR2001, Phillips, Phillips Electronic, Ltd., Thailand). Corn milk was separated from CMBP by hand pressing through a white cloth. CMBP in this step was called fresh-CMBP (F-CMBP).

\section{Powdered-CMBP process}

F-CMBP was dried in a tray dryer (Kluaynamthai Trading Group Co. Ltd., Bangkok, Thailand) at $70{ }^{\circ} \mathrm{C}$ for $8 \mathrm{~h}$, after which the moisture content reached $5.0 \pm 1 \%$ (wet basis). Dried-CMBP was powdered using a cereal grinder (Model: RRHP 500A, FNB Machinery and Solution Co. Ltd., Thailand), and then sieved to 80-mesh size.

\section{WWB formulation and process}

The sponge-dough bread was made as followed. The formulation of the control WWB was $210 \mathrm{~g}$ whole wheat flour (whole wheat flour), $1.65 \mathrm{~g}$ salt, $7 \mathrm{~g}$ dry yeast, $50 \mathrm{~g}$ honey, $33.30 \mathrm{~g}$ rice bran oil and $55 \mathrm{~g}$ of water. For the F-CMBP fortified formulations, 30, 60 and $90 \mathrm{~g}$ of F-CMBP (14, 28 and 42\% w/w whole wheat flour, respectively) was added to the control WWB formulation. For the P-CMBP fortified formulations, 30, 60 and $90 \mathrm{~g}$ of P-CMBP (14, 28 and $42 \% \mathrm{w} / \mathrm{w}$ whole wheat flour, respectively) was added to the control WWB formulation. The amount of water was adjusted to $180 \mathrm{~g}$ to obtain a dough formation with the least amount of water.

In the first step - making a sponge - a part of the total whole wheat flour (70 g) with yeast and water was combined in a mixer (Model: $5 \mathrm{k} 58 \mathrm{~s}$, Kitchen Aid, Michigan, USA) for 2 min. The sponge was proofed in an electric warmer cabinet (Kittiwattana Co. Ltd., Bangkok, Thailand) for $10 \mathrm{~min}$ at $45{ }^{\circ} \mathrm{C}$ and $70 \%$ relative humidity (RH). In the second step - making dough - the rest of the whole wheat flour (140 g) and other ingredients were combined in the mixer for 2 min and then combined with the proofed sponge. The mixture was kneaded by hand for $30 \mathrm{~min}$, followed by a second proofing in the electric warmer cabinet for $30 \mathrm{~min}$ at $45^{\circ} \mathrm{C}$ and $70 \% \mathrm{RH}$. One loaf of WWB was made in one batch of formulation. The dough was shaped by hand into an aluminum loaf baking pan and proofed in the electric warmer cabinet for $45 \mathrm{~min}$ at $45{ }^{\circ} \mathrm{C}$ and $70 \% \mathrm{RH}$. The dough was finally baked at $180{ }^{\circ} \mathrm{C}$ and $70 \% \mathrm{RH}$ for $30 \mathrm{~min}$ in a gas oven (Food Equipment Co. Ltd., Bangkok, Thailand), and cooled at room temperature for $50 \mathrm{~min}$ before analysis at 0 days of storage. WWB samples were kept in sealed polyethylene bags at room temperature for further analysis at 3 and 6 days of storage. 


\section{Dough and bread height measurement}

Dough heights, before and after proofing in aluminum pans, were manually measured at the middle height position of the dough. WWB heights were also manually measured at the middle height position of WWB. Three pieces of WWB bread loaves, at the left end, middle and right end, were measured at days 0,3 and 6 .

\section{Specific volume of WWB measurement}

Specific volumes of WWBs after cooling were calculated according to the AACC method 10-05.01 (AACC International, 2010) by dividing the volume $\left(\mathrm{cm}^{3}\right)$ by the weight $(\mathrm{g})$. The procedures involved weighing the WWB loaf, placing the loaf in a container filled with sesame seed to the maximum capacity of the container. The volume of the sesame seed, with and without the bread loaf was measured using a volumetric cylinder. The specific volume was calculated using the following equation:

$$
\text { Specific volume }=\frac{\left(V_{1}-V_{2}\right)}{\mathrm{W}}
$$

where $V_{1}$ is the volume $\left(\mathrm{cm}^{3}\right)$ of seed without one bread loaf.

$V_{2}$ is the volume $\left(\mathrm{cm}^{3}\right)$ of one bread loaf.

$\mathrm{W}$ is the weight $(\mathrm{g})$ of the bread.

\section{Color measurement}

The colors of the bread crust and crumbs were measured at days 0,3 and 6 using a Hunter color meter (Mini Scan XE plus, Hunter Associates Lab., Reston, Virginia, USA). The $\mathrm{L}^{*}, \mathrm{a}^{*}$ and $\mathrm{b}^{*}$ values were determined at crust and crumbs of the breads (modified method from Shittu et al., 2008). Crust color was measured at three positions (top, left and right side) in the middle position of loaf. The whole wheat loaf was cut to a thickness of $1 \mathrm{~cm}$. Crumb color was measured at three positions (middle top, right- and left-bottom corner) of three bread sheets. The standard black and white tiles supplied by the manufacturer were used for calibration before measurement.

\section{Texture analysis}

Texture analysis was evaluated with measurements from the bread firmnesscompression test method 74-10.02 (modified from AACC International, 2010) using a texture analyzer (Model TA-XT plus 10435, Stable Micro Systems Ltd., UK). The hardness of WWB samples (1 cm thickness) at days 0,3 and 6 were analyzed based on the force-time curve (Bouane, 1978) using a cylinder probe (Part code: $\mathrm{P} / 5 \mathrm{~S}$ ) of $5 \mathrm{~mm}$ diameter. 


\section{Moisture content analysis}

The moisture content of powdered-CMBP and WWB samples was analyzed according to the AACC approved method 44-15.02 (AACC International, 2010).

\section{Statistical analysis}

All determinations were made in triplicate in this study. Data were analyzed using one way analysis of variance with the SPSS version 12 software package (IBM Corporation, New York, USA). Mean comparisons were carried out using Duncan's multiple range test; statistical significance was defined as $P<0.05$.

\section{RESULTS}

The dough height before and after the final proofing in the aluminum pan is presented in Table 1. There was no significant difference $(P \geq 0.05)$ in the dough heights before proofing of the WWB samples fortified with F-CMBP and P-CMBP comparing to the control. After proofing at $45^{\circ} \mathrm{C}$ and $70 \% \mathrm{RH}$ for $45 \mathrm{~min}$, the dough height was re-measured. Dough expansion was found only in the control and the doughs added with 14 and 42\% P-CMBP. In contrast, doughs, fortified with 28\% F-CMBP, 42\% F-CMBP and 28\% P-CMBP had decreased height after proofing. This indicated the collapsed structure of the dough when these amounts and types of CMBPs were added. After baking, the bread height and bread specific volume are showed in Table 1. Control and 42\% P-CMBP-WWB had the greatest bread height, followed by the $14 \%$ F-CMBP added WWB samples, respectively. The high specific volume implied a porous structure of the bread. The specific volume of WWB was significantly improved with $14 \% \mathrm{~F}-\mathrm{CMBP}$ fortification with $35.75 \%$ increment compared to the control $(P<0.05)$. The WWB samples fortified with 28\% F-CMBP, 42\% F- CMBP and 14\% P-CMBP had a similar specific volume to the control $(P \geq 0.05)$.

The physical and textural characteristics of the WWB samples at 0,3 and 6 days of storage at room temperature (bread height, hardness, moisture content and color parameters) are depicted in Tables 2, 3 and 4. At 0 days of storage, the control WWB had the highest hardness value which was similar to $42 \%$ P-CMBP-WWB $(P \geq 0.05)$. However, the WWB samples fortified with all levels of F- CMBP and 14 and $28 \%$ of P-CMBP had lower hardness than the control $(P<0.05)$. This suggested that F-CMBP could be added up to $42 \%$, while no more than $28 \% \mathrm{P}-\mathrm{CMBP}$ could be to produce an improved, softer texture. 
Table 1. Dough and bread properties of WWB fortified with different levels of F-CMBP and P-CMBP.

\begin{tabular}{ccccc}
\hline WWBs & $\begin{array}{c}\text { Dough height } \\
\text { before proofing } \\
(\mathbf{c m})\end{array}$ & $\begin{array}{c}\text { Dough height } \\
\text { after proofing } \\
\mathbf{( c m})\end{array}$ & $\begin{array}{c}\text { Bread height } \\
\mathbf{( c m})\end{array}$ & $\begin{array}{c}\text { Bread specific } \\
\text { volume } \\
\left(\mathbf{c m}^{3} / \mathbf{g}\right)\end{array}$ \\
\hline Control & $4.3 \pm 0.4^{\mathrm{ab}}$ & $5.5 \pm 0.7^{\mathrm{ab}}$ & $5.4 \pm 0.4^{\mathrm{a}}$ & $1.79 \pm 0.03^{\mathrm{b}}$ \\
$14 \% \mathrm{~F}-\mathrm{CMBP}$ & $4.0 \pm 0.7^{\mathrm{ab}}$ & $4.0 \pm 1.4^{\mathrm{abcd}}$ & $4.3 \pm 1.2^{\mathrm{ab}}$ & $2.43 \pm 0.21^{\mathrm{a}}$ \\
$28 \% \mathrm{~F}-\mathrm{CMBP}$ & $3.3 \pm 0.4^{\mathrm{ab}}$ & $3.0 \pm 0.0^{\mathrm{cd}}$ & $3.8 \pm 0.0^{\mathrm{b}}$ & $1.96 \pm 0.02^{\mathrm{b}}$ \\
$42 \% \mathrm{~F}-\mathrm{CMBP}$ & $3.0 \pm 0.0^{\mathrm{b}}$ & $2.5 \pm 0.0^{\mathrm{d}}$ & $3.5 \pm 0.1^{\mathrm{b}}$ & $1.86 \pm 0.03^{\mathrm{b}}$ \\
$14 \% \mathrm{P}-\mathrm{CMBP}$ & $4.3 \pm 0.4^{\mathrm{ab}}$ & $4.7 \pm 0.2^{\mathrm{abc}}$ & $3.9 \pm 0.6^{\mathrm{b}}$ & $1.77 \pm 0.00^{\mathrm{b}}$ \\
$28 \% \mathrm{P}-\mathrm{CMBP}$ & $4.6 \pm 1.3^{\mathrm{ab}}$ & $3.8 \pm 1.1^{\mathrm{bcd}}$ & $3.8 \pm 0.3^{\mathrm{b}}$ & $1.41 \pm 0.03^{\mathrm{c}}$ \\
$42 \% \mathrm{P}-\mathrm{CMBP}$ & $4.9 \pm 0.6^{\mathrm{a}}$ & $5.8 \pm 0.4^{\mathrm{a}}$ & $5.5 \pm 0.1^{\mathrm{a}}$ & $1.16 \pm 0.04^{\mathrm{c}}$ \\
\hline
\end{tabular}

Note: Values $($ Mean \pm SD) with different lowercase superscript letters within the same column differ significantly $(P<0.05)$.

Fortifying with 14\% F-CMBP also resulted in the lowest hardness value for WWB, being $70.11 \%$ lower than the control. This indicated the fortification of F-CMBP and P-CMBP could produce an improved, softer texture of WWB, especially by adding 14\% F-CMBP. After 3 and 6 days of storage, all WWB samples had increased in hardness, but still had lower hardness than the control. The moisture content of the CMBP-fortified samples was higher than that of the control during the 6 days of storage. These high contents of moisture resulted from the humidity in F-CMBP and the higher volume of water in P-CMBP. During 3 and 6 days of storage, moisture loss was observed. Approximately $3 \%$ moisture loss was found in all WWB samples.

The color parameter of bread crust and crumbs were described using L* $(0$, black; 100, white), a* (-, greenness; +, redness) and b* (-, blueness; +, yellowness). There was an increase in the $\mathrm{L}^{*}$ values of the crust at days 0,3 and 6 , when fortified with CMBP. However, adding F-CMBP resulted in an increment in the $\mathrm{L}^{*}$ values of bread crust $(P \geq 0.05)$, while the WWB fortified with $42 \%$ P-CMBP had the highest $\mathrm{L}^{*}$ values for bread crust and higher $\mathrm{L}^{*}$ values than the control $(P<0.05)$. Similarly, CMBP fortification increased the $\mathrm{b}^{*}$ values, but decreased $\mathrm{a}^{*}$ values, indicating an increment in the yellowness and a decrement in the redness of WWB samples. Bread crumb colors are shown in Table 4. CMBP had a reverse result on the $\mathrm{L}^{*}$ values, but the amount of CMBP seemed not to affect the $\mathrm{L}^{*}$ value. After storage, an increase in the $\mathrm{L}^{*}$ value was observed. The $\mathrm{a}^{*}$ values were similar in all WWB samples, except 42\% P-CMBP after 3 and 6 days. A noticeable increment in the $b^{*}$ value was observed in the P-CMBP samples for all days of storage time $(P \geq 0.05)$. 


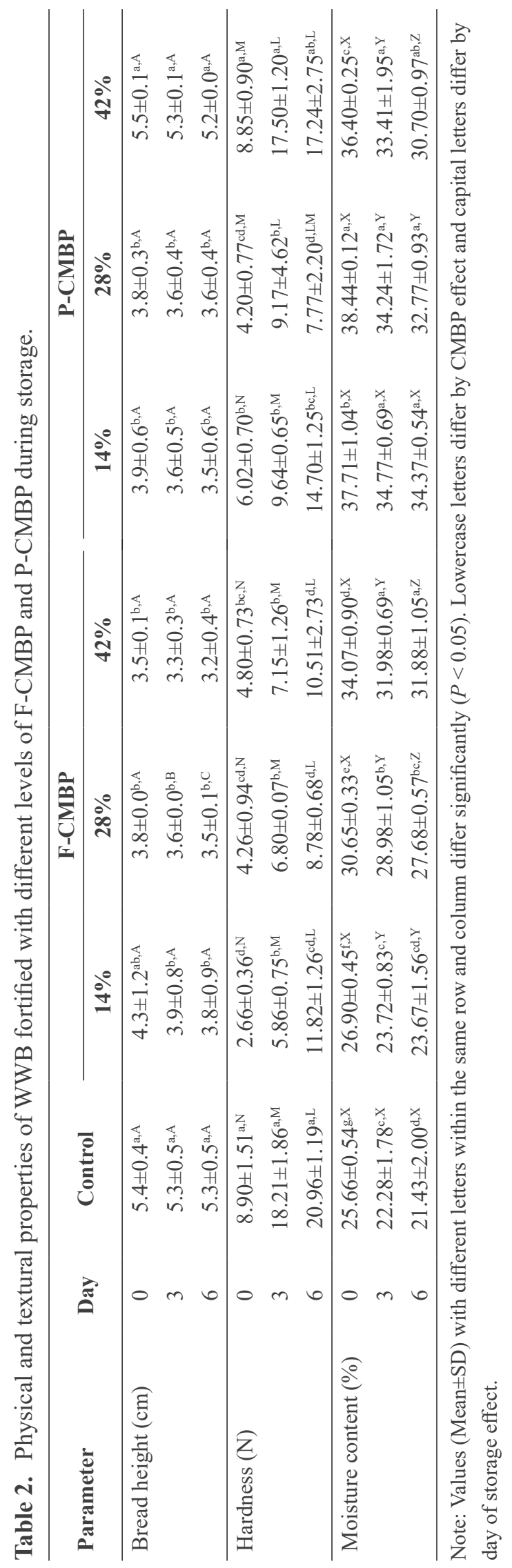




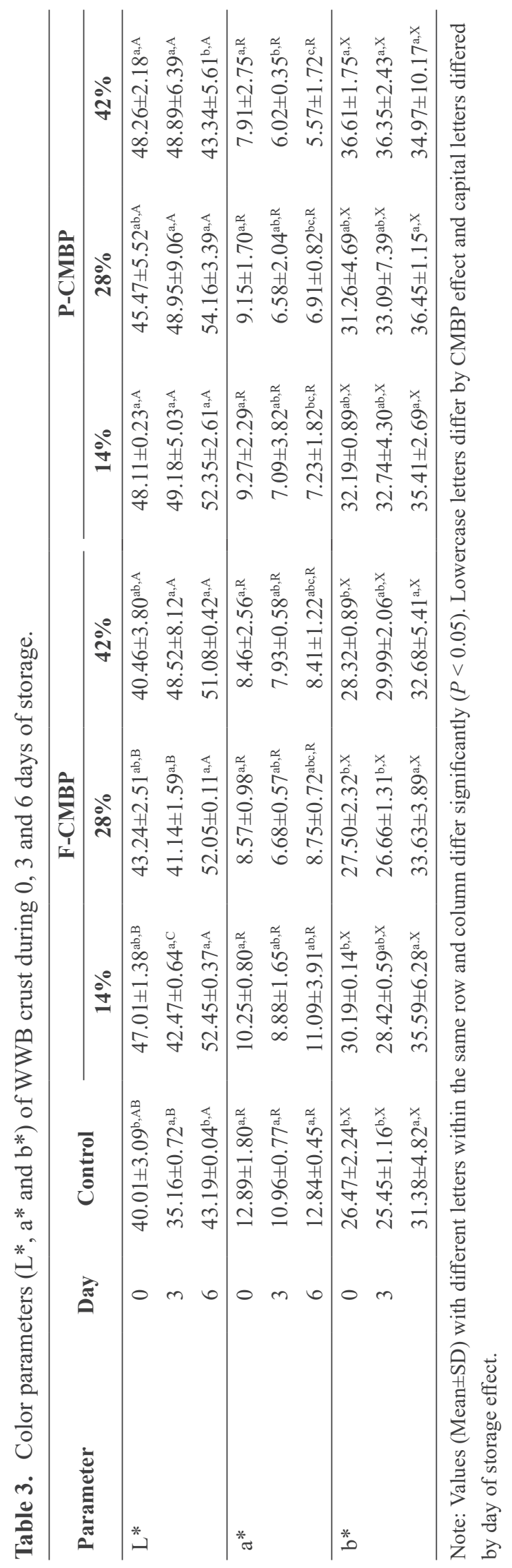




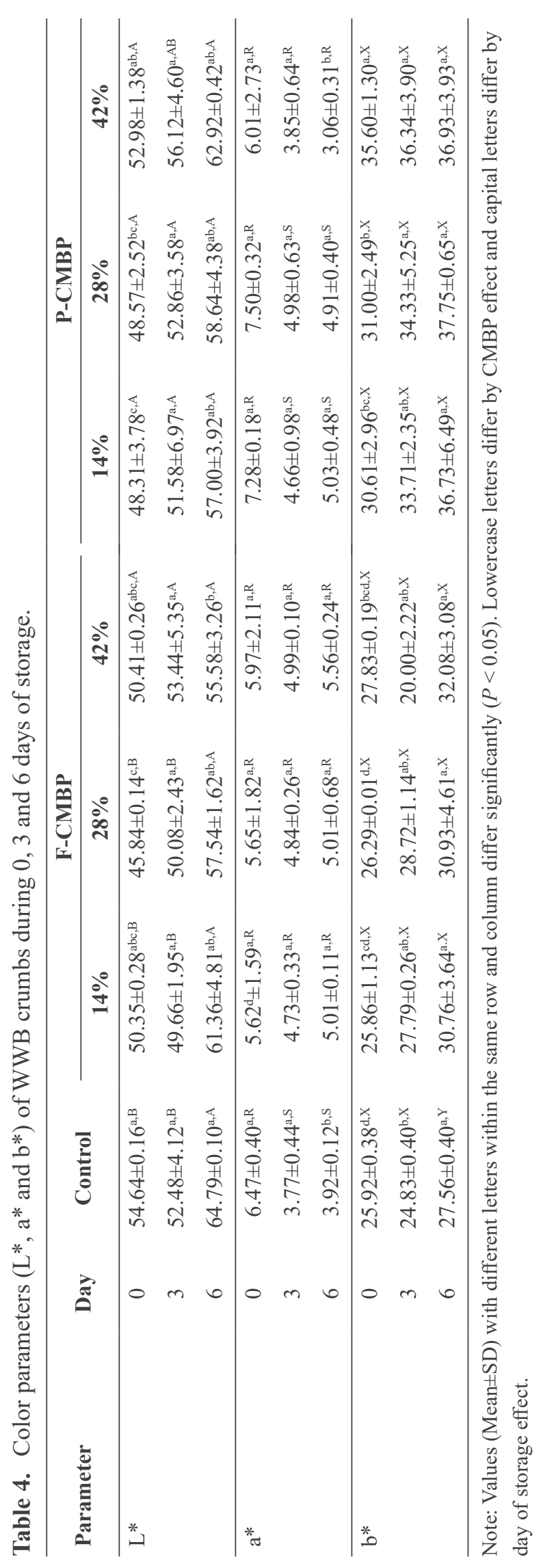




\section{DISCUSSION}

The effect of corn milk by product addition on the physical and textural properties of whole wheat dough and breads were determined in this study. Dough formation is a process affecting the quality of the bread. According to Table 1, the dough expansion was dominant in the control and 42\% P-CMBP samples. This indicated the low ability of dough forming and gas retention when fortified CMBP was used. Fortification with 28 and 42\% F-CMBP caused a reduction in the dough height after proofing. This might have been due to rupturing of the gluten structure of the whole wheat dough caused by the large F-CMBP particle size, especially in the fiber which made up approximately $10 \%$ in whole corn kernel (Naves et al., 2011). This result was in agreement with Martínez et al. (2014) who reported the rupture of dough added with large-coarse insoluble fiber. The bread height of the control was close to that of the $42 \%$ P-CMBP samples. This result was not due to the enhancing effect of $42 \% \mathrm{P}-\mathrm{CMBP}$ in dough forming ability, but rather to the high content of solids that increased the dough height as indicated by the low specific volume of the $42 \%$ P-CMBP samples and by observation. A low specific volume implies a dense, packed bread structure. The 14\% F-CMBP WWB samples had the highest specific volume, with a $35.75 \%$ increase compared to the control, although the dough expansion and bread height were lower than the control. This might have been due to the large porosity of the 14\% F-CMBP WWB samples and the strong crust structure of the bread when it was fortified with a suitable amount. A better specific volume than the control was also observed in the $28 \%$ F-CMBP WWB samples, but it slightly decreased when $42 \%$ F-CMBP was used for fortification $(P \geq 0.05)$. A greater amount of P-CMBP decreased the specific volume of the WWB samples due to the solid content from P-CMBP disrupting the dough structure and continuing to decrease the volume of the WWB samples. This could have been caused by the addition of non-gluten ingredients which lowered the dough forming ability of the wheat flour (Păucean and Man, 2013). Bressiani et al. (2017) reported that the particle size of whole wheat flour effect on bread volume resulted in bread with finer particles, which had more pronounced adverse effects on the bread volume compared to a medium or coarse particle size of the whole wheat flour. It has been suggested that finer particles in whole wheat flour results in a larger contact surface and the increased release of reactive compounds due to cell rupture interactions, with the gluten-forming proteins changing their functionality. This might be a reason why the WWB samples fortified with P-CMBP had a lower bread specific volume than those fortified with F-CMBP or the control.

The texture properties of the WWB samples were evaluated. It was found that the hardness of WWB was reduced in all fortified WWB samples except those with 42\% P-CMBP. The least hardness was recorded with 14\% F-CMBP at day 0. Similar results were presorted by Kim et al. (2015) who found that the use of corn starches to replace portions of rice flour in gluten-free breads resulted in lower hardness than without adding corn starch. However, F-CMBP produced a better result in reducing hardness than P-CMBP, possibly due to the particle size of P-CMBP being lower than that of F-CMBP. Particle size refinement also enhances the competition of the fibers for water with the gluten proteins, inhibiting their formation, since sufficient water availability is required for the development of the gluten network (Noort et al., 2010). The reduction in hardness could relate to the gelatinization of the starch remaining in the CMBP in the presence of heat and water. Moreover, the protein gelation of CMBP 
was also an important factor in reducing hardness. Siddiq et al. (2009b) reported the gelling capability of defatted corn germ flour increased with the defatting process. After 3 and 6 days of storage, the hardness values increased indicating bread staling during storage. However, fortified WWB samples had lower hardness values than the control, which could have been to the water absorbing capacity of CMBP (Siddiq et al., 2009b; Păucean and Man, 2013) which could help retard bread staling. Sabanis et al. (2009) reported that the addition of fiber in bread showed a high water-holding capacity in gluten-free breads, minimized water loss during storage, and led to a delayed retrogradation of starch. However, Martínez et al. (2014) suggested combining soluble fiber with a hydrocolloid to obtain greater stability in glutenfree dough. This could help to improve the textural quality of WWB. The moisture content of the WWB samples differed with the amount of water presented in F-CMBP, P-CMBP and used in bread making. The moisture content of F-CMBP was $75-80 \%$. The proper amount of water had a significant effect on dough rheology and bread quality. It contributed to starch phase dispersion, the gluten network and interactions between the components (Siddiq et al., 2009b).

The color parameters of WWB samples are shown in Tables 3 and 4. An increase in the crust $\mathrm{L}^{*}$ value was observed with CMBP fortification, leading to a lightening of the bread crust of the WWB samples. This could have been due to the natural color pigment found in corn which could reduce the darkness of the bread crust as supported by the increase in the yellowness as the $b^{*}$ values increased. However, the $L^{*}$ values of the crumbs seemed to decrease with CMBP fortification. A Maillard reaction and caramelization could play a major role in browning (Michalska et al., 2008) by the addition of sugar from CMBP and was related to the decrement in the $\mathrm{L}^{*}$ value. During storage, the crust and crumb color seemed to pale according to the increase in L* which indicated bread staling (Popov-Raljić et al., 2009).

\section{CONCLUSION}

CMBP is an interesting ingredient to use in food products. This study was designed to use CMBP in two forms -fresh and powdered- to fortify WWB. The textural and physical properties of WWB were evaluated. Fortification with $14 \% \mathrm{~F}-\mathrm{CMBP}$ resulted in the greatest reduction in hardness and a high specific volume of WWB. This study could be informative regarding improving the quality of WWB and other products in the future.

\section{REFERENCES}

AACC International. 2010. Approved methods of analysis. Method 10-05.01, 10-11.01, 4415.02, and 74-10.02, $11^{\text {th }}$ ed. AACC International, St. Paul.

Barnwal, P., Kore, P., and Sharma, A. 2013. Effect of partially de-oiled maize germ cake flour on physico-chemical and organoleptic properties of biscuits. Journal of Food Processing and Technology. 4:221. https://doi.org/10.4172/2157-7110.1000221

Bernstein, A.J., and Rose, D.J. 2015. Preference mapping of commercial whole wheat bread. Cereal Chemistry. 32(3): 278-283. https://doi.org/10.1094/CCHEM-07-14-0148-R 
Bouane, M.C. 1978. Texture profile analysis. Food Technology. 32(7): 62-66.

Bressiani, J., Oro, T., Santetti, G.S., Almeida, J.L., Bertolin, T.E., Gómez, M., and Gutkoski, L.C. 2017. Properties of whole grain wheat flour and performance in bakery products as a function of particle size. Journal of Cereal Science. 75: 269-277. https://doi.org/ 10.1016/j.jcs.2017.05.001

Demirkesen, I., Mert, B., Sumnu, G., and Sahin, S. 2010. Utilization of chestnut flour in gluten-free bread formulations. Journal of Food Engineering. 101(3): 329-336. https:// doi.org/ 10.1016/j.jfoodeng.2010.07.017

Kim, M., Yun, Y., and Jeong, Y. 2015. Effects of corn, potato, and tapioca starches on the quality of gluten-free rice bread. Food Science and Biotechnology. 24(3): 913-919. https://doi.org/10.1007/s10068-015-0118-8

Martínez, M.M., Díaz, A., and Gómez, M. 2014. Effect of different microstructural features of soluble and insoluble fibres on gluten-free dough rheology and bread-making. Journal of Food Engineering. 142: 49-56. https://doi.org/10.1016/j.jfoodeng.2014. 06.020

Michalskaa, A., Amigo-Benaventb, M., Zielinskia, H., and del Castillo, M.D. 2008. Effect of bread making on formation of Maillard reaction products contributing to the overall antioxidant activity of rye bread. Journal of Cereal Science. 48: 123-132. https://doi. org/10.1016/j.jcs.2007.08.012

Naves, M.M.V., de Castro, M.V.L., de Mendonca, A.L., Santos, G.G., and Silva, M.S. 2011. Corn germ with pericarp in relation to whole corn: nutrient contents, food and protein efficiency, and protein digestibility-corrected amino acid score. Ciência e Tecnologia de Alimentos. 31(1): 264-269. https://doi.org/10.1590/S0101-20612011000100040

Noort, M.W.J., Haaster, D.V., Hemery, Y., Schols, H.A., and Hamer, R.J. 2010. The effect of particle size of wheat bran fractions on bread quality-evidence for fibre-protein interactions. Journal of Cereal Science. 52: 59-54. https://doi.org/10.1016/j.jcs.2010. 03.003

Pathak, D., Majumdar, J., Raychaudhuri, U., and Chakraborty, R. 2016. Characterization of physicochemical properties in whole wheat bread after incorporation of ripe mango peel. Journal of Food Measurement and Characterization. 10: 554-561. https://doi.org/ 10.1007/s11694-016-9335-y

Păucean, A., and Man, S. 2013. Influence of defatted maize germ flour addition in wheat: maize bread formulations. Journal of Agroalimentary Processes and Technologies. 19(3): 293-304.

Popov-Raljić, J.V., Mastilović, J.S., Laličić-Petronijević, J.G., and Popov, V.S. 2009. Investigations of bread production with postponed staling applying instrumental measurements of bread crumb color. Sensors. 9(11): 8613-8623. https://doi.org/10. 3390/s91108613

Sabanis, D., Lebesi, D., and Tzia, C. 2009. Effect of dietary fibre enrichment on selected properties of gluten-free bread. LWT-Food Science and Technology. 42: 1380-1389. https://doi.org/10.1016/j.lwt.2009.03.010

Shittu, T.A., Aminu, R.A., and Abulude, E.O. 2009. Functional effects of xanthan gum on composite cassava-wheat dough and bread. Food Hydrocolloids. 23(8): 2254-2260. https://doi.org/10.1016/j.foodhyd.2009.05.016 
Shittu, T.A., Dixon, A., Awonorin, S.O., Sanni, L.O., and Maziya-Dixon, B. 2008. Bread from composite cassava-wheat flour. II: effect of cassava genotype and nitrogen fertilizer on bread quality. Food Research International. 41: 569-578. https://doi.org/10.1016/ j.foodres.2008.03.008

Siddiq, M., Nasir, M., Ravi, R., Butt, M.S., Dolan, K.D., and Harte, J.B. 2009a. Effect of defatted maize germ flour addition on the physical and sensory quality of wheat bread. LWT - Food Science and Technology. 42: 464-470. https://doi.org/10.1016/j.lwt.2008. 09.005

Siddiq, M., Nasir, M., Ravi, R., Dolan, K.D., and Butt, M.S. 2009b. Effect of defatted maize germ addition on the functional and textural properties of wheat flour. International Journal of Food Properties. 12: 860-870. https://doi.org/10.1080/10942910802103028

Yaseen, A.A., Shouk, A.A., and Ramadan, M.T. 2010. Corn-wheat pan bread quality as affected by hydrocolloids. Journal of American Science. 6(10): 721-727. 